\title{
O PAPEL SOCIAL DA LEITURA E DA ESCRITA: A QUESTÃO DO LETRAMENTO
}

Ilana da Silva Rebello (UFF)

Resumo: A preocupação com o analfabetismo funcional levou os pesquisadores ao conceito de "letramento" em lugar de "alfabetização". Nas sociedades letradas, ser alfabetizado é insuficiente para vivenciar plenamente a cultura escrita e responder às demandas da sociedade. Mas, o que é letramento? O que é uma pessoa letrada? Quais as diferenças entre alfabetizar e letrar? Dados do INAF - Indicador Nacional de Alfabetismo Funcional - mostram que os brasileiros têm dificuldades para entender e interpretar o que leem, independentemente do grau de escolarização. Nem sempre conseguem relacionar texto e contexto, fazendo inferências a fim de alcançarem o sentido global do texto. Partindo-se desses dados, o presente trabalho é uma reflexão sobre o processo de leitura e interpretação na sala de aula. Estaremos discutindo, então, os conceitos de letramento e alfabetização. Atrelado a esses dois conceitos, abordaremos a importância de o professor incentivar os alunos à leitura e à escrita de diferentes gêneros textuais. Palavras-chave: Linguística Textual; Letramento; Alfabetização; Ensino.

Abstract: The concern with functional illiteracy has led researchers to the concept of "literacy" in place of "initial reading instruction". In literate societies, being literate is not enough sufficient to fully experience the written culture and to respond to social demands. But what is literacy? What is a literate person? What are the differences between initial reading instruction and literacy? The INAF - National Indicator of Functional Literacy - shows that Brazilians have difficulties to understand and interpret what they read, independently of their schooling level. They can not always relate text and context, making inferences in order to reach the global meaning of the text. So, this paper is a reflection about the reading and interpretation process in the classroom. We will be discussing, then the concepts of literacy and initial reading instruction. Tying these two concepts, we will address the importance of the teacher's stimulation of students to the reading and writing different texts genres.

Keywords: Text Linguistics; Literacy; Initial Reading Instruction; Teaching. 
Por que é tão importante saber escrever, ler e interpretar? Por que a dificuldade dos alunos em entenderem o que leem preocupa tantos educadores? Qual a importância da leitura em nossa sociedade? Como está o nível de alfabetismo (leitura) dos brasileiros? Será que a deficiência em interpretar o que se lê é só de alguns grupos de alunos ou é um problema nacional? Tentaremos nos aprofundar um pouco mais nessas questões.

Atualmente, saber ler e escrever de forma mecânica temse revelado condição insuficiente para o indivíduo atender adequadamente às demandas da sociedade. Saber ler e escrever mecanicamente, ou seja, a mera decodificação, não garante a uma pessoa uma interação plena com os diferentes tipos de textos que circulam na sociedade. $O$ indivíduo precisa não só ser capaz de decodificar sons e letras, mas entender os significados e usos das palavras em diferentes situações.

Assim, o que falta a uma pessoa que sabe ler e escrever? Por que muitas pessoas, mesmo tendo concluído a Educação Básica, não conseguem entender um pequeno texto como um anúncio, por exemplo, ou redigir uma simples carta? 0 indivíduo precisa não apenas ler e escrever palavras, mas ler e escrever a própria vida. Para Moacir Gadotti: 
$\mathrm{O}$ ato de ler é incompleto sem o ato de escrever. Um não pode existir sem o outro. Ler e escrever não apenas palavras, mas ler e escrever a vida, a história. Numa sociedade de privilegiados, a leitura e a escrita são um privilégio. Ensinar o trabalhador apenas a escrever o nome ou assiná-lo na carteira profissional, ensiná-lo a ler alguns letreiros na fábrica como perigo, atenção, cuidado, para que ele não provoque algum acidente e ponha em risco o capital do patrão não é suficiente... Não basta ler a realidade. É preciso escrevê-la. (GADOTTI Apud VARGAS 2000, p. 14) [Grifos da autora].

Sendo assim, a simples alfabetização, no sentido de aprender a ler e escrever de maneira mecânica, tornase insuficiente para inserir plenamente um indivíduo na sociedade. Muitos pesquisadores chegaram ao conceito de "letramento" em lugar de "alfabetização" a partir da preocupação com o analfabetismo funcional (terminologia que a Unesco recomendara nos anos 70 e que o Brasil passou a usar somente a partir de 1990, segundo a qual a pessoa apenas sabe ler e escrever, sem saber fazer uso da leitura e da escrita). Segundo Soares (2000, p. 1), "se uma criança sabe ler, mas não é capaz de ler um livro, uma revista, um jornal, se sabe escrever palavras e frases, mas não é capaz de escrever uma carta, é alfabetizada, mas não é letrada.". 
Nesse sentido, nas sociedades letradas, reconhecer sons e letras é insuficiente para vivenciar plenamente a cultura escrita e responder às demandas da sociedade. Mas, o que é letramento? Que é uma pessoa letrada? Quando se pode dizer que uma criança ou um adulto estão letrados? É possível trabalhar a leitura e a escrita letrando?

Mesmo que não consigamos responder a todas essas questões, temos consciência de que é preciso um novo olhar, a fim de que o processo ensino-aprendizagem da leitura e da escrita nas escolas seja trabalhado de modo significativo tanto para crianças como para jovens e adultos. É preciso repensaro processo de interpretação textual nas escolas, ou seja, com quais conteúdos trabalhar a fim de desenvolvermos nos alunos a capacidade de inferir e chegar aos possíveis significados de um texto?

Qual a origem da palavra letramento?

A palavra "letramento", segundo Soares (2000, p. 15), surge no discurso dos especialistas nas áreas de Educação e de Ciências da Linguagem na segunda metade dos anos 80. Uma das primeiras ocorrências está no livro de Mary Kato $(1986$, p. 7) em que a autora afirma que “(...) a chamada norma-padrão, ou língua falada culta é consequência do letramento, motivo por que, indiretamente, é função da 
escola desenvolver no aluno o domínio da linguagem falada institucionalmente aceita".

Mesmo Kato não tendo definido o que é letramento, é interessante observar, a partir do que expõe a autora, que ser letrado não se trata apenas de saber ler e escrever. Por isso, a missão do professor é a de orientar o aluno na aquisição da flexibilidade linguística necessária ao desempenho adequado que Ihe será exigido em sociedade. Analisar diferentes textos, compará-los, pesquisar os porquês das diferenças, construir regras sobre o uso da língua e, a partir das descobertas, reescrever textos são práticas que produzem excelentes resultados na capacitação do aluno no uso da língua. Nesse sentido, letrar é mais que ensinar a ler e a escrever.

Dois anos depois da publicação de Mary Kato, em 1988, Leda Verdiani Tfouni publica um livro intitulado Adultos não alfabetizados: o avesso do avesso, em que, no capítulo introdutório, distingue alfabetização de letramento. Desde então, a palavra "letramento" torna-se cada vez mais frequente no discurso escrito e falado de especialistas, de tal forma que, em 1995, já figura como título de livro organizado por Ângela Kleiman e em outro escrito por Leda Verdiani Tfouni.

Afinal, de onde vem a palavra letramento? 
A palavra "letramento" é versão para o português da palavra da língua inglesa "literacy", que pode ser traduzida como a condição ou estado que assume aquele que aprende a ler e escrever. Segundo Soares (2000, p. 17), está implícita no conceito de "literacy" a ideia de que a escrita traz consequências sociais, culturais, políticas, econômicas, cognitivas, linguísticas, quer para o grupo social em que seja introduzida, quer para o indivíduo que aprenda a usá-la. Um indivíduo letrado é capaz de envolver-se nas práticas sociais de leitura e de escrita. Diante disso, qual a diferença entre letrado e alfabetizado?

É alfabetizado ou letrado? Letrar é mais que alfabetizar?

Alfabetizado é aquele indivíduo que sabe ler e escrever, já letrado é aquele que sabe ler e produzir textos, dos mais variados gêneros e temas. Um escritor competente deve saber selecionar o gênero apropriado a seus objetivos e à circunstância em que realizará seu discurso.

Letrar é mais que alfabetizar. A alfabetização deve se desenvolver em um contexto de letramento, como início da aprendizagem da escrita, como desenvolvimento de habilidades de uso da leitura e da escrita nas práticas sociais. Alfabetizar letrando é, portanto, ensinar a ler e escrever o mundo, ou seja, no contexto das práticas sociais 
da leitura e da escrita, tendo em vista que a linguagem é um fenômeno social.

O processo de ensino-aprendizagem de leitura e escrita na escola não pode ser configurado como um mundo à parte, mas deve ter a finalidade de preparar o sujeito para a realidade na qual se insere. Nesse contexto, cabe à escola propiciar ao aluno interação plena com diferentes tipos de textos e trabalhar com ele conteúdos para interpretar. $\mathrm{O}$ texto não pode servir apenas como pretexto para se trabalhar conteúdos gramaticais, pois existem, nele, conteúdos de interpretação textual.

É importante destacar que letramento não é um método. A discussão do letramento surge sempre envolvida com o conceito de alfabetização, o que tem levado a uma inadequada e imprópria síntese dos dois conceitos, com prevalência do conceito de letramento sobre o de alfabetização. Não podemos separar os dois processos, pois, a princípio, a inserção do aluno no universo da escrita e o desenvolvimento de habilidades de leitura e de escrita se dão, ao mesmo tempo, por meio desses dois processos: a alfabetização e o letramento.

O letramento inicia-se muito antes da alfabetização, ou seja, quando uma pessoa começa a interagir socialmente 
com as práticas de letramento no seu mundo social. Como afirma Freire (1989, p. 11-12),

[...] A leitura do mundo precede a leitura da palavra, daí que a posterior leitura desta não possa prescindir da continuidade da leitura daquele. Linguagem e realidade se prendem dinamicamente. A compreensão do texto a ser alcançada por sua leitura crítica implica a percepção das relações entre o texto e o contexto.

Nesse sentido, se a leitura do mundo precede a leitura da palavra, um indivíduo pode ser letrado, mas não alfabetizado. Por exemplo, um adulto, mesmo não sabendo ler e escrever, pode pedir a alguém que escreva por ele, dita uma carta, pede a alguém que leia para ele a carta que recebeu, ou uma notícia de jornal, ou uma placa na rua, ou a indicação do roteiro de um ônibus etc. Essa pessoa não sabe escrever e não sabe ler, mas já conhece as funções da escrita e da leitura, lançando mão do alfabetizado. Segundo Soares (2000, p. 47), essa pessoa é analfabeta, mas é, de certa forma, letrada, ou tem um certo nível de letramento. O mesmo acontece com crianças ainda não alfabetizadas. Para a autora

uma criança que vive num contexto de letramento, que convive com livros, que ouve histórias lidas por adultos, que vê adultos lendo e escrevendo, cultiva e exerce práticas de leitura e de escrita: 
toma um livro e finge que está lendo (...), toma papel e lápis e "escreve" uma carta, uma história. Ainda não aprendeu a ler e escrever, mas é, de certa forma, letrada, tem já um certo nível de letramento. (SOARES, 2000, p. 47)

Da mesma forma que é possível ter um certo nível de letramento e não ser alfabetizado, um indivíduo pode ser alfabetizado mas não ter um bom nível de letramento. É capaz de ler e escrever, porém não possui habilidades para práticas que envolvem a leitura e a escrita: não lê revistas, jornais, receitas de médico, bulas de remédio etc., ou seja, apresenta grande dificuldade para interpretar textos lidos, como também pode não ser capaz de escrever uma carta ou um bilhete.

Enfim, ser alfabetizado não é condição essencial para ser letrado. Na prática, vemos alunos que chegam ao Ensino Médio e não entendem o que leem. É preciso que o processo de leitura e escrita seja significativo, a fim de que o número de pessoas alfabetizadas e letradas em nossa sociedade seja cada vez maior. Enquanto não atribuir à leitura o verdadeiro valor que ela merece, a sociedade, de modo geral, continuará com a "mente fechada" e incorrendo nos mesmos erros de sociedades passadas. 
O INAF - Indicador Nacional de Alfabetismo Funcional

A iniciativa de criar um Indicador de Alfabetismo Funcional no Brasil, medindo diretamente as habilidades da população por meio de testes, foi tomada por duas organizações não governamentais, a Ação Educativa e o Instituto Paulo Montenegro.

Criado em 2001, o INAF/Brasil é baseado em entrevistas e testes cognitivos aplicados a amostras nacionais de 2000 pessoas representativas dos brasileiros entre 15 e 64 anos de idade residentes em zonas urbanas e rurais em todas as regiões do país. Focaliza habilidades de leitura/escrita e matemática.

O objetivo desse indicador é gerar informações que ajudem não só a compreender o alfabetismo funcional como também a orientar a formulação de políticas educacionais e propostas pedagógicas. Quais são as habilidades de leitura e escrita dos brasileiros? Quantos anos de escolaridade e que tipo de ação educacional garantem níveis satisfatórios de alfabetismo? Que outras condições favorecem o desenvolvimento de tais habilidades ao longo da vida?

Com base nos resultados do teste de leitura, o INAF classifica a população estudada em quatro níveis, como mostra a tabela a seguir: 
Analfabeto - corresponde à condição dos que não conseguem realizar tarefas simples que envolvem a leitura de palavras e frases, ainda que uma parcela destes consiga ler números familiares (números de telefone, preços, etc.).

Alfabetizado Nível Rudimentar - corresponde à capacidade de localizar uma informação explícita em textos curtos e familiares (como, por exemplo, um anúncio ou uma pequena carta), ler e escrever números usuais e realizar operações simples.

Alfabetizado Nível Básico - as pessoas classificadas neste nível podem ser consideradas funcionalmente alfabetizadas, pois já leem e compreendem textos de média extensão, localizam informações, mesmo que seja necessário realizar pequenas inferências.

Alfabetizado Nível Pleno - classificadas neste nível estão as pessoas cujas habilidades não mais impõem restrições para compreender e interpretar textos em situações usuais: leem textos mais longos, analisando e relacionando suas partes, comparam e avaliam informações, distinguem fato de opinião, realizam inferências e sínteses.

Tabela 1 - Níveis de alfabetismo

Fonte: INAF (www.ipm.org.br)

Os resultados do INAF/Brasil ao longo do período 20012012 mostram que os esforços em universalizar o acesso e estimular a permanência na escola têm produzido resultados na melhoria das capacidades de alfabetismo da população 
brasileira. Porém, mostram também que, além de ampliar o acesso, é preciso investir na qualidade, de modo que a escolarização garanta de fato as aprendizagens necessárias para que os cidadãos se insiram de forma autônoma e responsável na sociedade moderna.

No Brasil, muitos alunos concluem o Ensino Fundamental, mas não demonstram competências no processo de leitura e escrita. A tabela a seguir mostra a evolução do indicador para o Total Brasil no período de 2001 a 2011.

\begin{tabular}{|c|c|c|c|c|c|c|c|c|}
\hline \multicolumn{9}{|c|}{ Evolução do Indicador de alfabetismo da população de 15 a 64 anos (2001-2002 a 2011) } \\
\hline \multicolumn{2}{|c|}{ Nivels } & $2001-2002$ & $2002-2003$ & 2003-2004 & $2004-2005$ & 2007 & 2009 & 2011 \\
\hline \multicolumn{2}{|c|}{ BASES } & 2000 & 2000 & 2001 & 2002 & 2002 & 2002 & 2002 \\
\hline \multicolumn{2}{|c|}{ Analfabeto } & $12 \%$ & $13 \%$ & $12 \%$ & $11 \%$ & $9 \%$ & $7 \%$ & $6 \%$ \\
\hline \multicolumn{2}{|c|}{ Rudimentar } & $27 \%$ & $26 \%$ & $26 \%$ & $26 \%$ & $25 \%$ & $20 \%$ & $21 \%$ \\
\hline \multicolumn{2}{|c|}{ Básico } & $34 \%$ & $36 \%$ & $37 \%$ & $38 \%$ & $38 \%$ & $46 \%$ & $47 \%$ \\
\hline \multicolumn{2}{|c|}{ Pleno } & $26 \%$ & $25 \%$ & $25 \%$ & $26 \%$ & $28 \%$ & $27 \%$ & $26 \%$ \\
\hline $\begin{array}{l}\text { Analfabeto e } \\
\text { Rudimentar }\end{array}$ & $\begin{array}{l}\text { Analfabetos } \\
\text { funcionais }\end{array}$ & $39 \%$ & $39 \%$ & $38 \%$ & $37 \%$ & $34 \%$ & $27 \%$ & $27 \%$ \\
\hline $\begin{array}{l}\text { Básico e } \\
\text { Plono }\end{array}$ & $\begin{array}{l}\text { Alfabetlzados } \\
\text { funcionalmente }\end{array}$ & $61 \%$ & $61 \%$ & $62 \%$ & $63 \%$ & $66 \%$ & $73 \%$ & $73 \%$ \\
\hline
\end{tabular}

Tabela 2 - INAF BRASIL 2001 a 2011 - Fonte: INAF BRASIL (www.ipm.org.br)

De acordo com os dados colhidos pelo Instituto Paulo Montenegro, em 2001, havia 61\% da população brasileira alfabetizada funcionalmente. Em 2011, houve um avanço de $12 \%$, passando o indicador para $73 \%$. Sem dúvida, houve um avanço, porém a proporção dos que atingem um nível pleno de habilidades manteve-se praticamente inalterada, em torno de $26 \%$. 
Assim, de acordo com esses dados,

1. o número de brasileiros de 15 a 64 anos classificados peloINAF como "analfabetos absolutos" vem caindo ao longo dos anos, totalizando $6 \%$ no mais recente levantamento. Porém, o mesmo não vem ocorrendo de forma significativa com a parcela dos indivíduos classificados no nível rudimentar de alfabetismo, de 27\% em 2001, 25\% em 2007 para 21\% em 2011;

2. em relação ao nível básico de alfabetismo, houve um aumento, passando de 33\% em 2001 para 47\% em 2011;

3. o nível pleno tem oscilado por volta de $1 / 4$ do total de brasileiros: 26\% em 2001, 28\% em 2007 e 26\% em 2011. É um percentual ainda muito pequeno, tendo em vista que, no nível rudimentar e básico, as competências de leitura e escrita são bastante elementares. Isso significa que só $26 \%$ de 2000 pessoas entrevistadas apresentam boa capacidade de leitura e escrita.

Apesar de algumas melhorias nos níveis verificados, $68 \%$ da população brasileira ainda se encontra no nível rudimentar e básico. Isso significa dizer que essas pessoas só conseguem ler pequenos e médios textos e extrair inferências simples.

Internacionalmente, as medidas de alfabetismo funcional tomam por base os anos de estudo da população, considerando 
analfabetos funcionais as pessoas que não completaram, no Brasil, o 5ㅇ Ano de Escolaridade. Supostamente, ao completar esta série, os alunos já deveriam dominar habilidades básicas de alfabetismo. Analogamente, espera-se que, ao concluir o Ensino Fundamental (9을 Ano de Escolaridade), tais habilidades atinjam um desenvolvimento que permita ao aluno uma inserção mais plena na cultura letrada.

Sem dúvida, quanto maior o nível de escolaridade, maior a chance de atingir bons níveis de alfabetismo. Porém, no Brasil, os dados do INAF do período de 2001 a 2011 mostram também que nem sempre o nível de escolaridade garante o nível de habilidades que seria esperado.

\section{Nivel de alfabetismo da população de 15 a 64 anos por escolaridade da populaçăo em 2011}

\begin{tabular}{|c|c|c|c|c|c|c|}
\hline \multirow{2}{*}{\multicolumn{2}{|c|}{ Niveis }} & \multicolumn{5}{|c|}{ Escolaridade } \\
\hline & & Nenhuma & $\begin{array}{c}\text { Ensino } \\
\text { FundamentalI }\end{array}$ & $\begin{array}{c}\text { Ensino } \\
\text { Fundamental II }\end{array}$ & Ensino Médio & $\begin{array}{l}\text { Ensino } \\
\text { Superior }\end{array}$ \\
\hline \multicolumn{2}{|c|}{ BASES } & 158 & 378 & 476 & 701 & 289 \\
\hline \multicolumn{2}{|c|}{ Analfabeto } & $54 \%$ & $8 \%$ & $1 \%$ & $0 \%$ & $0 \%$ \\
\hline \multicolumn{2}{|c|}{ Rudimentar } & $41 \%$ & $45 \%$ & $25 \%$ & $8 \%$ & $4 \%$ \\
\hline \multicolumn{2}{|c|}{ Básico } & $6 \%$ & $43 \%$ & $59 \%$ & $57 \%$ & $34 \%$ \\
\hline \multicolumn{2}{|c|}{ Pleno } & $0 \%$ & $5 \%$ & $15 \%$ & $35 \%$ & $62 \%$ \\
\hline $\begin{array}{l}\text { Analfabeto e } \\
\text { Rudlmentar }\end{array}$ & $\begin{array}{l}\text { Analfabeto } \\
\text { funclonal }\end{array}$ & $95 \%$ & $53 \%$ & $26 \%$ & $8 \%$ & $4 \%$ \\
\hline Básico e Pleno & $\begin{array}{l}\text { Alfabetizado } \\
\text { funclonalmente }\end{array}$ & $6 \%$ & $48 \%$ & $74 \%$ & $92 \%$ & $96 \%$ \\
\hline
\end{tabular}

Tabela 3 - Nível de escolaridade x nível de habilidades.

Fonte: INAF BRASIL (www.ipm.org.br)

A análise dos níveis de alfabetismo por grau de escolaridade evidencia a realidade da situação brasileira: 
1. mais da metade (53\%) dos brasileiros entre 15 e 64 anos que estudaram até o 5ㅇ Ano atinge, no máximo, o grau rudimentar de alfabetismo, ou seja, esses brasileiros possuem, no máximo, a habilidade de localizar informações explícitas em textos curtos e não são capazes de compreender textos mais longos e de localizar informações que exijam alguma inferência;

2. $8 \%$ dos que estudaram até o 50 Ano podem ser considerados analfabetos absolutos em termos de habilidades de leitura/escrita, não conseguindo nem mesmo decodificar palavras e frases, ainda que em textos simples;

3. dentre os que cursam ou cursaram do 6으 ao 9 은 Ano, apenas $15 \%$ pode ser considerado plenamente alfabetizado, enquanto a maioria se enquadra no nível básico de alfabetismo. Chama mais atenção o fato de que $25 \%$ dos que estão entre o 6ㅇ e o 9 ㅇ Ano ainda permaneçam no nível rudimentar;

4. $35 \%$ dos que cursaram ou estão cursando o Ensino Médio conseguiram atingir o nível pleno de alfabetismo (esperado para 100\% deste grupo), enquanto 57\% ainda permanecem no nível básico;

5. somente prevalecem, entre os que chegam ou completaram o Ensino Superior, 62\% dos indivíduos com 
pleno domínio das habilidades de leitura/escrita, o que também levaria a esperar que fossem $100 \%$. Os dados ainda mostram, nessa etapa de escolaridade, $4 \%$ no nível rudimentar e 34\% no nível básico de leitura e escrita.

Tais resultados do INAF reforçam a hipótese inicial deste trabalho de que as pessoas, de um modo geral, têm dificuldades para entender e interpretar o que leem, independentemente do grau de escolarização.

Diante disso, qual o papel do professor na formação não só de alfabetizados, como também de letrados? Como trabalhar a leitura e a escrita letrando? Se a educação é um processo contínuo, que só termina com a morte do indivíduo, como então fazer com que esse indivíduo sempre se interesse pelas práticas de leitura e de escrita? Como ajudá-lo a viver numa sociedade grafocêntrica?

O papel do educador na formação de indivíduos letrados

Numa sociedade letrada, o objetivo do ensino deve ser o de aprimorar a competência e melhorar o desempenho linguístico do estudante, tendo em vista a integração e a mobilidade sociais dos indivíduos.

O ensino da leitura e da escrita deve ser entendido como prática de um sujeito que age sobre o mundo para 
transformá-lo e para, por meio da sua ação, afirmar a sua liberdade e fugir à alienação.

É através da prática que desenvolvemos nossa capacidade linguística. Conhecer diferentes tipos de textos não é, pois, decorar regras gramaticais e listas de palavras. No rap "Estudo Errado", Gabriel, o Pensador, diz com propriedade: “Decorei, copiei, memorizei, mas não entendi. Decoreba: este é o método de ensino. Eles me tratam como ameba e assim eu num raciocino".

É lamentável que, no Brasil, a escola, lugar fundamental para a pessoa desenvolver sua capacidade de linguagem, continue limitando-se, na maioria das vezes, a um ensino mecânico. Na perspectiva do letramento, a leitura e a escrita são vistas como práticas sociais.

O objetivo de se ensinar a ler e a escrever deve estar centrado em propiciar ao estudante a aquisição da língua portuguesa, de maneira que ele possa exprimir-se corretamente, aconselhado pelo professor por meio de estímulos à leitura de variados textos, nos quais serão verificadas as diferentes variações linguísticas, tornando-se um "poliglota em sua língua" (BECHARA, 1999), para que, ao dominar o maior número de variantes, ele possa ser capaz de interferir socialmente nas diversas situações a que for submetido. 
A educação, sendo uma prática social, não pode restringirse a ser puramente livresca, teórica, sem compromisso com a realidade local e com o mundo em que vivemos. Educar é também um ato político. É preciso resgatar o verdadeiro sentido da educação. De acordo com Freire (1989, p. 589), “(...) o ato de estudar, enquanto ato curioso do sujeito diante do mundo, é expressão da forma de estar sendo dos seres humanos, como seres sociais, históricos, seres fazedores, transformadores, que não apenas sabem mas sabem que sabem".

Assim, quando os alunos são o sujeito da própria aprendizagem, "seres fazedores, transformadores", no dizer de Paulo Freire, tomam consciência de que sabem e podem transformar o já feito, construído. Deixam a passividade e a alienação para se constituírem como seres políticos.

Como afirma Freire (1996, p. 42), o diálogo é fundamental em qualquer prática social. Ele consiste no respeito aos educandos, não somente enquanto indivíduos, mas também enquanto expressões de uma prática social:

(...) A grande tarefa do sujeito que pensa certo não é transferir, depositar, oferecer, doar ao outro, tomado como paciente de seu pensar, a inteligibilidade das coisas, dos fatos, dos conceitos. A tarefa coerente do educador que pensa certo é, 
exercendo como ser humano a irrecusável prática de inteligir, desafiar o educando com quem se comunica e a quem comunica, produzir sua compreensão do que vem sendo comunicado. Não há inteligibilidade que não seja comunicação e intercomunicação e que não se funde na dialogicidade. $O$ pensar certo por isso é dialógico e não polêmico. (FREIRE, 1996, p, 2).

O professor precisa despertar no aluno a curiosidade, a vontade de aprender, pois, como afirma Safady (Apud SILVA 2005, p. 44), “(...) o leitor curioso e interessado é aquele que está em constante conflito com o texto, conflito representado por uma ânsia incontida de compreender, de concordar, de discordar - conflito, enfim, onde quem lê não somente capta o objeto da leitura, como transmite ao texto lido as cargas de sua experiência humana e intelectual".

Assim, a partir do momento em que o aluno perceber a riqueza de conhecimentos e de prazer que pode encontrar na leitura, compreenderá que “(...) ler é (...) não só uma ponte para a tomada de consciência, mas também um modo de existir no qual o indivíduo compreende e interpreta a expressão registrada pela escrita e passa a compreender-se no mundo" (SILVA, 2005, p. 45).

Em uma educação significativa, o aluno não pode ser um simples objeto nas mãos do professor. É o que Freire (1996) 
chama de "educação bancária", isto é, o educando, ao receber passivamente os conhecimentos, torna-se um depósito do educador. "Ensinar não é transferir conhecimentos, mas criar as possibilidades para sua produção ou a sua construção" (FREIRE, 1996, p. 52). Como afirma Martins,

(...) aprender a ler significa também aprender a ler o mundo, dar sentido a ele e a nós próprios, o que, mal ou bem, fazemos mesmo sem ser ensinados. A função do educador não seria precisamente a de ensinar a ler, mas a de criar condições para o educando realizar a sua própria aprendizagem, conforme seus próprios interesses, necessidades, fantasias, segundo as dúvidas e exigências que a realidade lhe apresenta. Assim, criar condições de leitura não implica apenas alfabetizar ou propiciar acesso aos livros. Trata-se, antes, de dialogar com o leitor sobre a sua leitura, isto é, sobre o sentido que ele dá, repito, a algo escrito, um quadro, uma paisagem, a sons, imagens, coisas, ideias, situações reais ou imaginárias. (MARTINS, 1994, p. 34)

O trabalho escolar, no domínio da interpretação e da produção de linguagem, faz-se sobre os gêneros. Eles constituem o instrumento de mediação de toda estratégia de ensino e o material de trabalho, necessário e inesgotável, para o ensino da textualidade. O problema está em como 
os professores trabalham esses variados gêneros textuais. Infelizmente, a prática tem-nos mostrado que, em muitas salas de aula, o texto tem sido um pretexto para o ensino de gramática e não é explorado em suas múltiplas possibilidades de sentido.

Tal problema é detectado por muitos educadores e pesquisadores, como Kleiman (2004, p. 56), levando-a a afirmar que

se o aluno é capaz de decodificar o texto escrito, se ele é capaz de utilizar a informação sintática do texto na leitura, e se, ademais, ele já completou a aquisição da língua materna, as dificuldades que ele revela na compreensão do texto escrito são decorrentes de estratégias inadequadas de leitura. A prática mencionada, a utilização do texto como pretexto da aula de gramática, certamente contribui para a formação de estratégias de leitura inadequadas, pela ênfase que coloca nos aspectos sequenciais e distribucionais dos elementos linguísticos do texto, justamente aqueles elementos que não são constitutivos do texto enquanto unidade de significação. (KLEIMAN, 2004, p. 56)

Não é à toa que, segundo Vargas (2000, p. 7-8), a estrutura educacional brasileira tem formado mais ledores que leitores. Para a autora, a diferença entre uns e outros está 
na qualidade da decodificação, no modo de sentir e de perceber o que está escrito. O leitor, diferentemente do ledor, compreende o texto na sua relação dialética com o contexto, na sua relação de interação com a forma. O leitor adquire através da observação mais detida, da compreensão mais eficaz, uma percepção mais crítica do que é lido, isto é, chega à política do texto. A compreensão social da leitura dá-se na medida dessa percepção. Pois bem, na medida em que ajudo meu leitor, meu aluno, a perceber que a leitura é fonte de conhecimento e de domínio do real, ajudo-o a perceber o prazer que existe na decodificação aprofundada do texto. (VARGAS, 2000, p. 7-8)

Diante disso, como formar leitores? Se a "educação é transformação do homem e do mundo" (SILVA, 2005, p. 77), como fazer com que o aluno perceba as sutilezas em um texto?

Estamos de acordo com Silva (2005, p. 97) quando afirma que “(...) as crianças nunca chegam à escola num estado de ignorância, mas podem chegar analfabetas. Elas talvez não saiam analfabetas, mas podem sair ignorantes...".

Nesse sentido, para realizar um trabalho significativo de leitura, cabe ao professor mostrar aos alunos uma pluralidade de discursos. Trabalhar com diferentes textos possibilita 
ao professor fazer uma abordagem mais consciente das variadas formas de uso da língua. Assim, o professor pode transformar a sua sala de aula num espaço de descobertas e construção de conhecimentos.

A tarefa de selecionar materiais de leitura para os alunos é uma das tarefas mais difíceis. Nessa escolha, são postas em questão as diferentes concepções que tem cada professor sobre a aprendizagem, os processos de leitura, a compreensão, as funções dos textos e o universo do discurso. Além disso, coloca-se em jogo a representação que tem cada docente não só do desenvolvimento cognitivo e sócio-afetivo dos sujeitos a quem serão dirigidos os materiais, mas também dos interesses de leitura de tais destinatários. Dessa forma, também intervém como variável significativa o valor que o docente atribui aos materiais como recursos didáticos.

Trabalhar com gêneros textuais variados nos permite entender que a escolha de um gênero leva em conta os objetivos visados, o lugar social e os papéis dos participantes. Daí decorre a detecção do que é adequado ou inadequado em cada uma das práticas sociais.

Diante disso, na medida em que o educador tomar consciência de sua posição política, articulando conteúdos 
significativos a uma prática também significativa, desvinculando-se da função tradicional de mero transmissor de conteúdos e, consequentemente, de mero repetidor de exercícios do livro didático, estará transformando o ensino da leitura e da escrita. Um educador, como mediador, que parta da observação da realidade para, em seguida, propor respostas diante dela, estará contribuindo para a formação de pessoas críticas e participativas na sociedade.

Pelo exposto, fica claro que uma prática significativa depende do interesse do professor em planejar as suas aulas com coerência, visando à construção de conhecimentos com os alunos.

É importante destacar que letrar não é apenas função do professor de Língua Portuguesa. Em todas as áreas de conhecimento, em todas as disciplinas, os alunos aprendem por meio de práticas de leitura e de escrita: em História, em Geografia, em Ciências, mesmo em Matemática, enfim, em todas as disciplinas, os alunos aprendem lendo, interpretando e escrevendo.

Letrar é função de todos os professores, mesmo porque, em cada área de conhecimento, a escrita e a leitura têm peculiaridades que só os professores que nela atuam conhecem e dominam. 
(...) nós, professores de todas as áreas, em vez de nos limitarmos a choramingar que nossos alunos não têm o hábito da leitura, devemos nos dedicar a proporcionar muitas e muitas oportunidades para que todos descubram que ler é uma atividade muito interessante, que a leitura nos proporciona prazer, diversão, conhecimento, liberdade, uma vida melhor, enfim. E essas oportunidades terão de ser tantas quantas forem necessárias para que o aluno passe a gostar de ler e, por isso, contraia a necessidade da leitura e que esta vire hábito.

Isso é tarefa do professor de português? É. É tarefa do professor de história, de geografia, de ciências, de artes, de educação física, de matemática... É tarefa da escola: (...). (GUEDES \& SOUZA, 2007, p. 19)

O educador, reeducando-se e transformando-se, deixará de vez suas tarefas e as funções da educação sob a ótica das elites econômicas, culturais e políticas das classes dominantes, em direção a uma prática libertadora. Assim, o ensino cessará de ser um martírio para se tornar um processo de construção permanente de conhecimentos. O educador deve estimular no aluno o pensamento crítico, de modo que ele possa atuar na sociedade como um indivíduo pensante, questionador. 
Enfim, nos dias atuais, o conhecimento é uma das "ferramentas" para se conquistar oportunidades de trabalho e renda. Assim, aos professores cabe a responsabilidade de fazer com que seus alunos se interessem pela leitura e pela escrita de diferentes textos e que sejam capazes de interpretar o que leem. Acreditamos, assim, que "o compromisso primeiro do professor de língua materna é auxiliar o aluno a tornar-se um leitor autônomo e um produtor competente de textos" (FIORIN, 1996, p. 9).

\section{REFERÊNCIAS}

Bechara, E. (1999). Moderna gramática portuguesa (37a ed.). Rio de Janeiro: Lucerna.

Fiorin, J. L. (1996). Teorias do discurso e ensino da leitura e da redação. In Gragoatá. (no 1). Niterói: EDUF.

Freire, P. (1996). Pedagogia da autonomia: saberes necessários à prática educativa. São Paulo: Paz e Terra.

(1989). A importância do ato de ler: em três artigos que se completam. São Paulo: Autores Associados.

Guedes, P. C. \& Souza, J. M. de. (2007). Leitura e escrita são tarefas da escola e não só do professor de português. In I. C. B. Neves et alli. (Orgs.) Ler e escrever: compromisso de todas as áreas (8a ed.). Porto Alegre: Editora da UFRGS.

INAF - Relatório INAF (2011): Indicador de Alfabetismo Funcional Principais resultados. São Paulo: Instituto Paulo Montenegro; Ação Educativa. In www.ipm.org.br. Acesso em abril/2015.

Kato, M. (1986). No mundo da escrita: uma perspectiva psicolinguística. (Série Fundamentos). São Paulo: Ática. 
Kleiman, Â. B. (2004). Leitura: ensino e pesquisa (2a ed.). Campinas: Pontes.

Martins, M. H. (1994). O que é leitura. São Paulo: Brasiliense.

Silva, E. T. da. (2005). Elementos de pedagogia da leitura. São Paulo: Martins Fontes.

Soares, M. (2000). Letramento: um tema em três gêneros (2a ed.). Belo Horizonte: Autêntica.

Vargas, S. (2000). Leitura: uma aprendizagem de prazer (4a ed.) Rio de Janeiro: José Olympio.

Ilana da Silva Rebello é graduada em Letras (2002- UFF), mestre (2005UFF) e doutora (2009-UFF) em Língua Portuguesa pela Universidade Federal Fluminense. Já atuou como professora de Língua Portuguesa na Prefeitura de São Gonçalo, na Prefeitura de Niterói, na Secretaria Estadual de Educação e na Fundação de Apoio à Escola Técnica (FAETEC). Atualmente é professora Adjunta II 40h DE, de Língua Portuguesa do Departamento de Letras Clássicas e Vernáculas da Universidade Federal Fluminense. Está vinculada à linha de pesquisa Teorias do texto, do discurso e da interação do Programa de Pós-graduação em Estudos da Linguagem da Universidade Federal Fluminense. Atua também no curso de especialização em Língua Portuguesa. Coordena o Programa de Iniciação à Docência, vinculado ao Instituto de Letras/UFF e é vicecoordenadora do Curso de Pós-Graduação Lato Sensu em Língua Portuguesa (Quadriênio 2015-2019). Tem experiência na área de Letras, com ênfase em Língua Portuguesa, atuando principalmente nos seguintes temas: semiolinguística, mídia, leitura, interpretação e escrita. 